\title{
Perceived social support and health-related quality of life (HRQoL) in Tehranian adults: Tehran lipid and glucose study
}

Sara Jalali-Farahani ${ }^{1}$, Parisa Amiri ${ }^{1 *}$, Mehrdad Karimi ${ }^{1,2}$, Golnaz Vahedi-Notash ${ }^{1}$, Golshan Amirshekari ${ }^{3}$ and Fereidoun Azizi ${ }^{3}$

\begin{abstract}
Background: Several studies have demonstrated the positive association between perceived social support and health-related quality of life (HRQoL) in certain groups; however, few studies have assessed this relationship in general population and between genders. This study aimed to investigate associations between socio-demographic factors, perceived social support and HRQoL among an urban Iranian population.

Methods: The study population were 1036 adults who had participated in Tehran Lipid and Glucose Study (TLGS). Data on socio-demographic information, perceived social support and HRQoL were collected using standard questionnaires by trained interviewers. Perceived social support and HRQoL were assessed using Iranian versions of the Multidimensional Scale of Perceived Social Support (MSPSS) and Short-Form 12-Item Health Survey version 2 (SF-12v2) respectively. Data on sets of associations among socio-demographic factors, perceived social support and quality of life were analyzed using Structural Equation Modeling (SEM) with IBM SPSS AMOS software.
\end{abstract}

Results: Mean ages were $50.3 \pm 16.3$ and $49.6 \pm 14.0$ years in men and women respectively and $40.9 \%$ of participants were male. In terms of perceived social support scores, except for family subscale scores $(p=0.003)$, there were no significant differences between men and women. However, men had significantly higher HRQoL scores, compared to women in all subscales. The findings of SEM analysis demonstrated that being married in both genders $(p<0.001)$ and lower age in men $(p<0.05)$ were significantly associated with higher level of perceived social support. In terms of physical HRQoL, being single and higher perceived social support in both genders and lower age and not having any chronic diseases, only in women were associated with higher physical HRQoL. However, for mental HRQoL, age and perceived social support had significant direct associations with mental HRQoL in both genders $(p<0.001)$; in women, being single $(p<0.05)$ and not having chronic diseases $(p<0.001)$ were also significantly associated with better mental HRQOL.

Conclusion: Perceived social support was found to be both directly and indirectly associated with physical and mental aspects of HRQoL in both genders. Current structural models provide beneficial information for planning health promotion programs aimed at improving HRQoL among Tehranian adults.

Keywords: Socio-demographic factors, Social support, Health-related quality of life, Adults, Iran

\footnotetext{
* Correspondence: amiri@endocrine.ac.ir

${ }^{1}$ Research Center for Social Determinants of Health, Research Institute for

Endocrine Sciences, Shahid Beheshti University of Medical Sciences, P.O.Box:

19395-4763, Tehran, IR, Iran

Full list of author information is available at the end of the article
}

(C) The Author(s). 2018 Open Access This article is distributed under the terms of the Creative Commons Attribution 4.0 International License (http://creativecommons.org/licenses/by/4.0/), which permits unrestricted use, distribution, and reproduction in any medium, provided you give appropriate credit to the original author(s) and the source, provide a link to the Creative Commons license, and indicate if changes were made. The Creative Commons Public Domain Dedication waiver (http://creativecommons.org/publicdomain/zero/1.0/) applies to the data made available in this article, unless otherwise stated. 


\section{Background}

Following the sweeping changes worldwide in the pattern of illnesses and the rising prevalence of non-communicable diseases (NCDs) over the past decades, the medical framework has been changed and besides life expectancy, quality of life (QOL) has become critically important [1, 2]. Accordingly, beyond measurable objective outcomes, such as mortality and clinical functions, improving health-related quality of life (HRQoL) as an individuals' self-evaluation of physical, mental, and social health status based on their experiences and perceptions, is now the ultimate goal of disease prevention programs being considered at different levels of health care [3-5].

Different demographic, psychological, environmental and social relations and conditions are known to be associated with HRQoL by data available in general populations and those with specific diseases in different stages of life [6-12]. Among these factors, findings regarding the influence of social support on individuals' disease recovery, coping resources and HRQoL are remarkable [7, 8, 13-17]. Social support as a multidimensional construct encompasses the kind of interpersonal interaction and relationship, individual's belief that he/she is cared for and loved, esteemed and valued, and is a part of the communication network [18-20]. Two main aspects of received and perceived social support have been considered in current literature; while received social support implies the particular supportive behavior which is provided to recipients by their supportive networks, perceived social support, as a subjective part of this concept, refers to the recipient's perceptions regarding how existing support is made available to satisfy their needs [21, 22].

Several studies have demonstrated that in both Western and Eastern communities, perceived social support is positively associated with HRQoL in certain groups, e. g. those with acute or chronic diseases [23-31], elderly populations [32, 33], immigrant workers and employees $[34,35]$; however, few studies have assessed this relationship in general population and between genders $[6,36]$. In this regard a community-based study conducted on a large population of American adults showed that compared to women, men reported better HRQoL as well as higher level of social support; however, there were no significant differences in the association between these two concepts between genders [36]. On the contrary, another study revealed a higher predictive power of social support for women's QoL than for men, in an Italian population [6]. In addition, sex, age, educational level and job status were among the main socio-demographic indices which could improve physical or mental aspects of HRQoL [31].

HRQoL and social support as cultural and value-based concepts have been separately addressed only in a few Iranian studies. Those investigations that aimed to investigate the relation of these concepts in Iranian population have been focused on the particular employees, patients on hemodialysis, and those with coronary heart disorders and HIV [35, 37-40]. In this regard, considering the glaring lack of data on this relationship among general Iranian populations, this study assessed the hypothesized model which examined the network of associations among socio-demographic variables, social support and HRQoL in Iranian men and women by structural equation modeling.

\section{Methods}

The population of this study were adults (> 19 years), participants of the Tehran Lipid and Glucose Study (TLGS), a community-based study designed and conducted among residents of district No. 13 of Tehran, aimed at determining the risk factors and prevention of non-communicable diseases [41]. Of TLGS participants who participated during 2015-2016 $(n=1139)$, after excluding outliers $(n=31)$ and missing data $(n=72)$, all adults participants who had complete data on Short-Form 12-Item Health Survey version 2 (SF-12v2) and Multidimensional Scale of Perceived Social Support (MSPSS) were recruited for current study $(n=1036)$. Prior to data collection, the ethics committee of the Research Institute for Endocrine Sciences (RIES) of Shahid Beheshti University of Medical Sciences approved the study and all participants signed an informed consent form.

Socio-demographic information (age, marital status, employment status and level of education) and data on perceived social support and health-related quality of life of participants were collected by trained interviewers, using standard questionnaires. Having chronic diseases was defined as diagnosed cancer, chronic kidney diseases, diabetes, hypertension and history of cardiovascular diseases. Perceived social support was assessed using the MSPSS developed by Zimet et al.. The MSPSS encompasses 12 items and three subscales. Each subscale includes four items and assesses perceived social support from three different sources including family, friends and significant others. For scoring each item, a sevenpoint scale ranging from 1 (very strongly disagree) to 7 (very strongly agree) was used. The minimum and maximum total scores for the scale are 12 and 84 respectively and a higher total score indicates higher perceived social support. In the current study, the Iranian version of MSPSS was used; its validity and reliability have been reported in a previous study [42].

HRQoL was assessed using the SF-12v2, which is a generic measure of perceived health status, consisting of 12 items and eight subscales including physical functioning, role physical, bodily pain, general health, vitality, social functioning, role emotional and mental health. The subscale scores ranged from 0 to 100 , indicating the 
lowest and highest level of health measured by the scale. Physical component summary (PCS) and mental component summary (MCS) scores were calculated using the appropriate scoring algorithms. Validity and reliability of the Iranian version of SF-12v2 has been reported previously [43].

\section{Statistical analysis}

For continuous variables, mean \pm SD and for categorical ones, frequency (percent) were reported as descriptive statistics. Means of continuous and the distribution of categorical variables were compared between genders using the Independent samples t-test and the ChiSquare test respectively. Associations between sociodemographic, social support and quality of life scales were examined using Structural Equation Modeling (SEM) [44]. As shown in the conceptual frame work of the inter-relationship between variables (Fig. 1), social support and HRQoL were considered as latent constructs and social support was considered as mediator in the relationship between socio-demographic and HRQoL. To test the hypothesized model across gender groups and compare them, SEM multiple-group analysis was applied. In the first model (unconstrained model), all parameters were considered different in men and women. In the multiple group modeling, some constraints about parameters equality between men and women were considered. Constrained models were defined as follows: Measurement weights model: Equal factor loadings for measurement model of social support and quality of life constructs in men and women; Structural weights model: Equal factor loadings and regression weights between latent variables in men and women; Structural covariance model: Equal covariance for latent constructs in men and women; Structural residuals model: Equal residual variances for latent constructs in men and women and the measurement residuals model: All parameters were considered equal in men and women. Fit indices of SEM models after modifying were calculated and compared to their acceptable thresholds [45]. Statistical analysis and computations were done by IBM SPSS Statistics \& AMOS version 22 .

\section{Results}

Of 1036 participants, $40.9 \%$ were male and mean ages were $50.3 \pm 16.3$ and $49.6 \pm 14.0$ years in men and women respectively. Descriptive statistics for sociodemographic variables, perceived social support and HRQoL scores are presented in Table 1. Mean age and distribution of marital status did not differ significantly in men and women; however, there were significant differences in distributions of level of education and employment status. Most men and women had secondary education and a higher percentage of men (34.0\%) had higher education compared to women (29.1\%). In terms of employment status, majority of women were housewives (70.9\%) and majority of men were employed (66.3\%). About half of both men (42.5\%) and women (50.7\%) had chronic diseases with significantly higher prevalence in women compared to men $(p<0.05)$. In terms of social support scores, except for social family subscale scores $(p=0.003)$, there were no significant differences between men and women. However, as indicated in Table 1 , in all subscales of HRQoL, men had significantly higher HRQoL scores compared to women $(p<0.001)$.

The results of model comparison and fit indices of structural model considering different constraints are

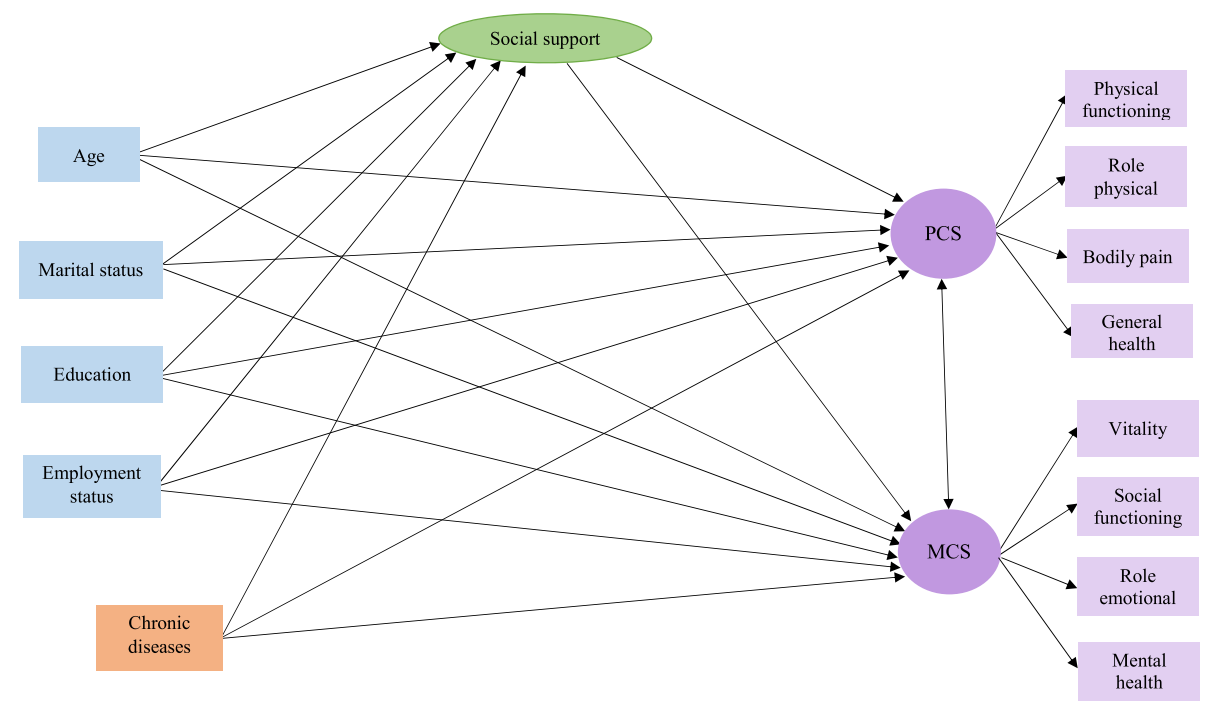

Fig. 1 Conceptual model for the association between socio-demographic factors, social support health-related quality of life (HRQoL) 
Table 1 Descriptive statistics of study participants

\begin{tabular}{|c|c|c|c|}
\hline & Male $(n=424)$ & Female $(n=612)$ & $P$ value \\
\hline Age (years) & $50.3 \pm 16.3$ & $49.6 \pm 14.0$ & 0.52 \\
\hline \multicolumn{4}{|l|}{ Marital status n(\%) } \\
\hline -Single & $83(19.6)$ & $139(22.7)$ & \multirow[t]{2}{*}{0.257} \\
\hline -Married & $341(80.4)$ & $473(77.3)$ & \\
\hline \multicolumn{4}{|l|}{ Level of education n(\%) } \\
\hline -Primary & $109(25.7)$ & $208(34.0)$ & \multirow[t]{3}{*}{0.016} \\
\hline -Secondary & $171(40.3)$ & $226(36.9)$ & \\
\hline -Higher & $144(34.0)$ & $178(29.1)$ & \\
\hline \multicolumn{4}{|l|}{ Employment status n(\%) } \\
\hline $\begin{array}{l}\text { - Unemployed/student/ } \\
\text { housewife }\end{array}$ & $32(7.5)$ & $434(70.9)$ & \multirow[t]{3}{*}{$<0.001$} \\
\hline $\begin{array}{l}\text { - Unemployed, but had } \\
\text { other sources of income }\end{array}$ & $111(26.2)$ & $71(11.6)$ & \\
\hline - Employed & $281(66.3)$ & $107(17.5)$ & \\
\hline \multicolumn{4}{|l|}{ Chronic diseases } \\
\hline$-\mathrm{No}$ & $244(57.5)$ & $302(49.3)$ & \multirow[t]{2}{*}{0.011} \\
\hline -Yes & $180(42.5)$ & $310(50.7)$ & \\
\hline Social support scores & $65.8 \pm 12.2$ & $64.6 \pm 12.6$ & 0.15 \\
\hline - Family & $24.0 \pm 4.3$ & $23.2 \pm 4.8$ & 0.003 \\
\hline - Friend & $19.1 \pm 6.0$ & $19.2 \pm 6.2$ & 0.88 \\
\hline -Significant other & $22.6 \pm 5.3$ & $22.3 \pm 5.7$ & 0.32 \\
\hline \multicolumn{4}{|l|}{ SF-12 scores } \\
\hline -Physical Function & $87.2 \pm 22.9$ & $80.6 \pm 25.2$ & $<0.001$ \\
\hline -Role Physical & $84.6 \pm 20.5$ & $73.3 \pm 24.1$ & $<0.001$ \\
\hline -Bodily pain & $85.1 \pm 21.0$ & $75.4 \pm 24.7$ & $<0.001$ \\
\hline -General Health & $49.9 \pm 22.2$ & $45.2 \pm 22.5$ & $<0.001$ \\
\hline PCS & $49.6 \pm 7.3$ & $47.2 \pm 8.5$ & $<0.001$ \\
\hline -Vitality & $69.2 \pm 24.4$ & $60.5 \pm 25.9$ & $<0.001$ \\
\hline -Social Function & $84.3 \pm 24.9$ & $77.5 \pm 27.1$ & $<0.001$ \\
\hline -Role Emotional & $80.3 \pm 22.2$ & $71.0 \pm 24.2$ & $<0.001$ \\
\hline -Mental Health & $74.8 \pm 20.3$ & $65.7 \pm 22.1$ & $<0.001$ \\
\hline MCS & $50.6 \pm 9.6$ & $46.5 \pm 11.1$ & $<0.001$ \\
\hline
\end{tabular}

Continuous variables are represented as mean \pm SD and the categorical ones are presented as frequency (percentage)

PCS Physical component summary, MCS Mental component summary

presented in Table 2. All evaluations about associations and the conceptual frame work of the inter-relationship between variables are reported based on the unconstrained model. In the unconstrained model (all parameters were considered different in men and women) we achieved acceptable fit indices and compared to one of constrained models entitled "measurement weights" (equal factor loadings allowed for measurement models of social support and quality of life constructs in men and women), no statistical difference was observed between two models $\left(\Delta \mathrm{X}^{2}=12.96, \mathrm{DF}=8, P=0.11\right)$. All other constrained models were statistically different from the unconstrained one and the model with different parameters between men and women had better fit indices.

All hypothesized associations in the conceptual model among socio-demographic variables, perceived social support and HRQoL are demonstrated in Fig. 1; perceived social support, PSC and MCS were considered as latent constructs in the model. Figure 2 indicates structural models after testing the association between sociodemographic factors, social support and HRQoL by gender. Fit indices for SEM in men $\left(\chi^{2}=298.2, d f=79\right.$, $\mathrm{X}^{2} / \mathrm{df}=3.77, \quad \mathrm{CFI}=0.88, \quad \mathrm{GFI}=0.92, \quad \mathrm{RMSEA}=0.08$, SRMR $=0.08)$ and women $\left(\chi^{2}=300.7, \mathrm{df}=79, \chi^{2} / \mathrm{df}=3.80\right.$, CFI $=0.92, \quad$ GFI $=0.94, \quad$ RMSEA $=0.07, \quad$ SRMR $=0.06$ ) display acceptable fit for hypothesized models in gender groups. Only significant associations and their corresponding coefficients $(\beta)$ are drawn in Fig. 2. The findings of structural equations modeling analysis are summarized as follows: In terms of social support, being married in both men $(\beta=0.33 ; p<0.001)$ and women $(\beta=0.16 ; p<0.001)$ and lower age, only in men $(\beta=-0.19 ; p<0.05)$ were significantly associated with higher level of perceived social support. PCS and MCS were significantly correlated in both men $(r=0.74 ; p<0.001)$ and women $(r=0.63 ; p<0.001)$. In terms of PCS, being single and higher perceived social support in both genders and lower age and not having any chronic diseases only in women, were significantly associated with higher physical HRQoL scores. In terms of MCS, higher age and higher perceived social support were significantly associated with better mental HRQoL scores in both genders; however, in women, being single and not having chronic diseases were also significantly associated with better mental HRQoL scores.

The effect differences between men and women were tested using multi-group analysis. Standardized coefficients and their corresponding critical ratios (CR) for each gender are reported in Table 3. Findings indicate that the effect of age on physical HRQoL and the effects of chronic diseases and social support on mental HRQoL were significantly different between men and women with higher effects in women, compared to men.

\section{Discussion}

The present study aimed at testing a conceptual model of associations among socio-demographic factors, perceived social support and health-related quality of life (HRQoL) in an urban Iranian population. Based on our findings, marital status and social support in both genders and age and having chronic diseases only in women were factors directly associated with the physical aspect of HRQoL. Furthermore, age and social support in both genders and marital status and having chronic diseases only in women, were factors directly associated with the 
Table 2 Model comparison, fit indices and results of chi-square test for comparisons between the two models

\begin{tabular}{lllllllllll}
\hline Model & DF & $X^{2} / D F$ & RMSEA & SRMR & CFI & GFI & NFI & IFI & AIC & Model comparisons $\left(X^{2}, \mathrm{DF}\right)$ \\
\hline Unconstrained $^{\mathrm{a}}$ & 158 & 3.82 & 0.052 & 0.079 & 0.91 & 0.93 & 0.88 & 0.91 & 831.5 & Assuming to be correct \\
Measurement weights $^{\mathrm{b}}$ & 166 & 3.71 & 0.051 & 0.080 & 0.91 & 0.93 & 0.88 & 0.91 & 828.5 & $12.96, \mathrm{DF}=8$ \\
Structural weights $^{\mathrm{c}}$ & 183 & 3.53 & 0.050 & 0.083 & 0.91 & 0.92 & 0.87 & 0.91 & 823.5 & $41.94^{*}, \mathrm{DF}=25$ \\
Structural covariance $^{\mathrm{d}}$ & 196 & 5.30 & 0.064 & 0.096 & 0.83 & 0.90 & 0.80 & 0.83 & 1190.5 & $434.9^{* *}, \mathrm{DF}=38$ \\
Structural residuals $^{\mathrm{e}}$ & 200 & 5.28 & 0.064 & 0.098 & 0.83 & 0.89 & 0.80 & 0.83 & 1200.2 & $452.7^{* *}, \mathrm{DF}=42$ \\
Measurement residuals $^{\mathrm{f}}$ & 215 & 5.10 & 0.063 & 0.098 & 0.82 & 0.89 & 0.79 & 0.82 & 1209.9 & $492.5^{* *}, \mathrm{DF}=57$
\end{tabular}

Unconstrained model assuming to be correct, other proposed models ${ }^{\text {b-f }}$ were compared to unconstrained model using chi-square difference test

$D F$ degree of freedom, RMSEA root of mean square error approximation, SRMR standardized root mean square residual, CFI comparative fit index, GFI goodness of fit index, NFI normed fit index, IFI incremental fit index, AIC Akaike information criterion

${ }^{*} p<0.05,{ }^{* *} p<0.001$. ${ }^{a}$ All of the parameters were considered different in men and women, ${ }^{b}$ Equal factor loadings for measurement model of social support and quality of life constructs in men and women, ${ }^{c}$ Equal factor loadings and regression weights between latent variables in men and women, ${ }^{\mathrm{d} E q u a l}$ covariance for latent constructs in men and women, ${ }^{e}$ Equal residual variances for latent constructs in men and women ${ }^{f}$ All parameters were considered equal in men and women

mental aspect of HRQoL. These findings highlight the prominent role of perceived social support in both aspects of perceived health in Iranian adults.

In the current study, perceived social support from family and significant others were higher than friends. Recent findings imply that, compared to friends, family members and significant others are more important sources of perceived social support in our society. Moreover, current findings indicate no significant differences in perceived social support scores, except for social family subscale scores which were significantly higher in men, compared to women. Another study conducted among Tehranian medical personnel reported no gender differences in social support [35]. In terms of sociodemographic factors associated with perceived social support, marital status was significantly associated with perceived social support in both genders. Findings of higher perceived social support in Iranian married men and women, compared to their single counterparts are in line with other previous studies [46-48]. Furthermore, younger men perceived higher social support, compared to older men, implying that with increasing age, the ability of men to make social connections decreases.

In the current study, social support was significantly associated with both aspects of HRQoL in both genders, a finding in agreement with previous studies from different countries [7, 36]; other studies conducted on different Iranian populations $[35,49]$ also found that perceived social support was an important correlate of HRQoL; these findings indicate that we/us humans are "social beings" and having good social relations and strong social ties can influence both the physical and mental aspects of health. An interesting finding of the current study was the different gender specific effect of social support on the mental aspect of HRQoL which was significantly higher in women compared to men. Another study conducted in Iran also revealed that insufficient perceived social support was shown to be associated with postpartum depression disorder in Iranian women [50], findings emphasizing the importance of perceived social support on mental aspect of health in women.

Among socio-demographic factors, the current conceptual model indicated that only age and marital status were significantly and directly associated with HRQoL and socio-economic factors (assessed by level of education and employment in this study) were not significantly associated with HRQoL in both genders emphasizing the important roles of marital status and age, compared to socio-economic status in perception of health among Iranian adults. Although married individuals were consistently found to have better perception regarding their health status in previous studies [51, 52], our findings indicate that single individuals reported better HRQoL scores as single women reported higher HRQoL scores in both physical and mental HRQoL and men reported higher scores only in physical HRQoL. Current evidence indicates that perceived social support was found to be a mediator of this association [53], data in line with our findings. Another important and interesting finding of this study was that while previous studies consistently reported poorer HRQoL in individuals suffering from different chronic diseases [54-57]; based on the current conceptual model, no significant association was found between chronic diseases and HRQoL in men. However, in women, chronic diseases were associated with poorer HRQoL in both the physical and mental aspects indicating different patterns of association among HRQoL, perceived social support and other related factors in Iranian men and women.

In addition, based on gender specific analysis, factors including age, having chronic diseases and social support had significantly stronger effects on HRQoL in women, compared to men, implying more important roles for social factors in perception of health in women, compared to men.

Few studies in Iran have investigated the associations between perceived social support and HRQoL and those 

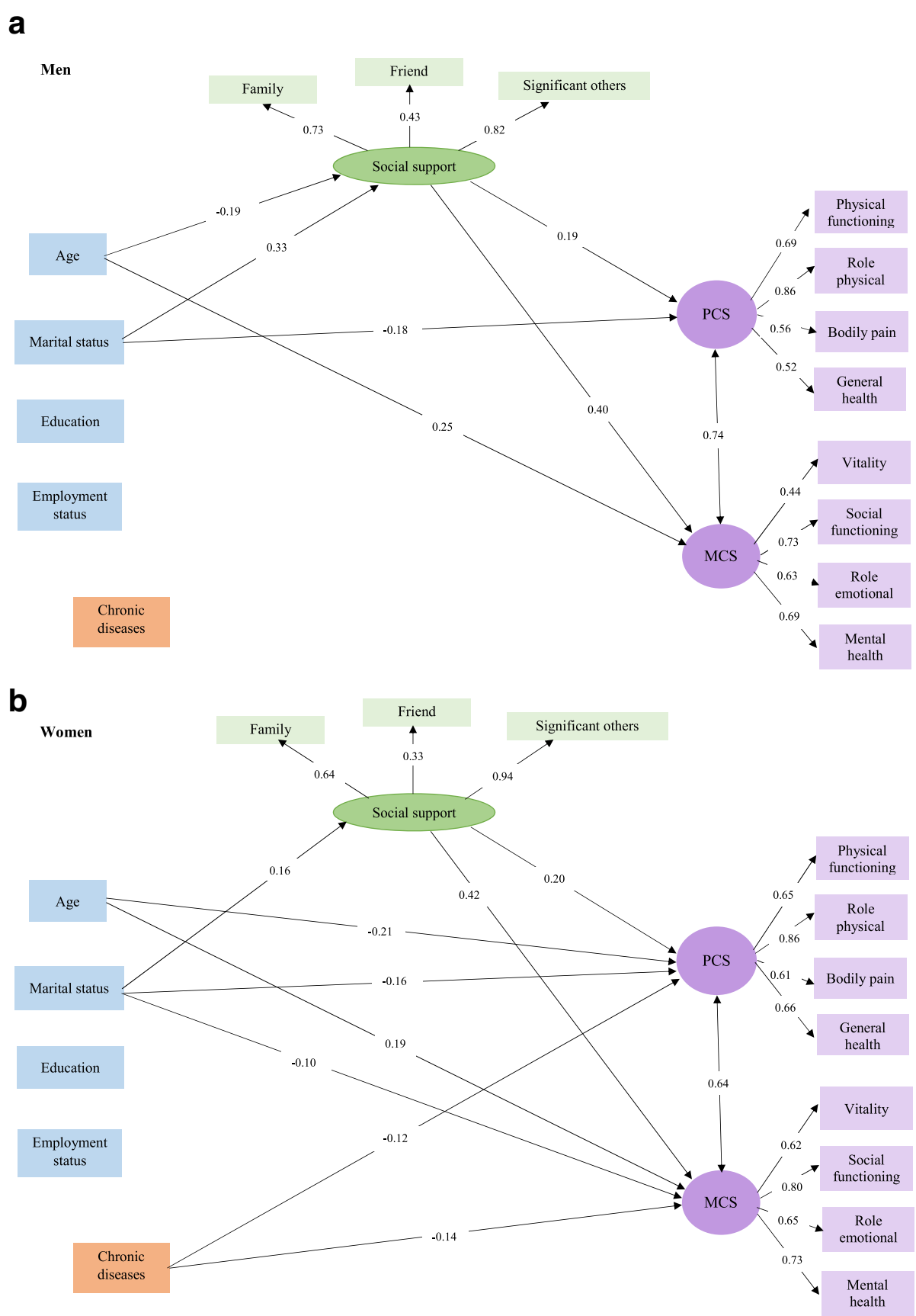

Fig. 2 Final structural models after testing the association between socio-demographic factors, social support and health-related quality of life (HRQoL) (a Men and b Women)

that did focused mainly on specific groups. The current study is among the first efforts that reports the associations among socio-demographic factors, perceived social support and health-related quality of life (HRQoL) in a general urban Iranian population with different socio-economic statuses. In interpreting the findings of this study, the following limitations should be considered; first, causality cannot be assumed from findings of this study due to its cross- sectional nature. More robust research designs, such as prospective cohorts or stepped wedge clusters are recommended to try and gauge causal relationships. Second, the participants of this study were limited to Tehranian adults and the results are not generalizable to other parts of Iran specifically rural areas; therefore, to consider these findings for policy making, conducting further studies in rural areas and other cities of Iran is definitely recommended. 
Table 3 Results of the structural equation modeling analysis: gender-specific relationships between socio-demographic factors, social support and HRQOL

\begin{tabular}{|c|c|c|c|c|c|c|}
\hline & & Male & & Female & & Difference \\
\hline & & Coefficient $\beta$ & $C R$ & Coefficient $\beta$ & $C R$ & \\
\hline Age & Social support & -0.191 & $-2.28^{*}$ & -0.041 & -0.65 & 1.32 \\
\hline Marital status ${ }^{a}$ & & 0.326 & $4.13^{* *}$ & 0.164 & $3.37^{* *}$ & -1.84 \\
\hline Education $^{\mathrm{b}}$ & & -0.006 & -0.10 & 0.066 & 1.16 & 0.87 \\
\hline Employment status $^{c}$ & & -0.070 & -1.19 & -0.017 & -0.33 & 0.80 \\
\hline Chronic diseases $^{\mathrm{d}}$ & & 0.041 & 0.64 & 0.079 & 1.44 & 0.43 \\
\hline Age & PCS & -0.034 & -0.44 & -0.216 & $-3.70^{* *}$ & $-2.16^{*}$ \\
\hline Marital status & & -0.179 & $-2.43^{*}$ & -0.164 & $-3.75^{* *}$ & 0.15 \\
\hline Education & & 0.081 & 1.48 & 0.077 & 1.47 & -0.02 \\
\hline Employment status & & 0.063 & 1.17 & -0.019 & -0.41 & -1.19 \\
\hline Chronic diseases & & -0.088 & -1.49 & -0.122 & $-2.43^{*}$ & -0.46 \\
\hline Social support & & 0.193 & $3.15^{* *}$ & 0.201 & $4.54^{* *}$ & 0.26 \\
\hline Age & MCS & 0.245 & $2.82^{* *}$ & 0.185 & $2.95^{* *}$ & 0.53 \\
\hline Marital status & & -0.067 & -0.87 & -0.096 & $-2.06^{*}$ & -0.71 \\
\hline Education & & -0.050 & -0.86 & 0.083 & 1.47 & 1.70 \\
\hline Employment status & & 0.027 & 0.47 & -0.026 & -0.52 & -0.70 \\
\hline Chronic diseases & & -0.004 & -0.06 & -0.144 & $-2.64^{* *}$ & $-2.04^{*}$ \\
\hline Social support & & 0.397 & $4.90^{* *}$ & 0.422 & $7.54^{* *}$ & $2.09^{*}$ \\
\hline$P C S^{e}$ & & 0.744 & $6.05^{* *}$ & 0.634 & $8.26^{* *}$ & 1.18 \\
\hline
\end{tabular}

PCS Physical component summary, MCS Mental component summary

${ }^{*} p<0.05,{ }^{* *} p<0.001$, ${ }^{a}$ Single group was considered as reference group, bHigher education was considered as reference group, ${ }^{c}$ Unemployed group was considered as reference group, ${ }^{\mathrm{d}}$ Not having chronic diseases was considered as reference group, ${ }^{\mathrm{e}}$ correlation coefficient

Moreover, in the current study, paired structure of data for couple participants was not considered which could affect the current results. To tackle this limitation, correlated data models such as random effects SEM recommended to be applied in future studies with large number of pairs or couples. Finally, as some other potential factors associated with HRQoL such as income level and gender-specific psychosocial conditions and opportunities were not included in the model, assessing these related factors is also recommended in future studies in this field.

\section{Conclusion}

In conclusion, among social factors considered in this study, age, marital status and perceived social support were significant determinants of both physical and mental HRQoL. Additionally, chronic diseases were associated with HRQoL only in women. The current structural model provide beneficial information for planning future health promotion programs aiming at improving HRQoL among Tehranian adults. Considering the nature of other significant social determinants of HRQoL, only social support can be included in intervention programs. Therefore, designing interventions aimed at helping individuals to foster their social network and make better social ties, especially with their family members are recommended.

\section{Abbreviations}

HRQoL: Health-related quality of life; MCS: Mental component summary; MSPSS: Multidimensional Scale of Perceived Social Support; PCS: Physical component summary; SEM: Structural Equation Modeling; SF-12v2: ShortForm 12-Item Health Survey version 2; TLGS: Tehran Lipid and Glucose Study

\section{Acknowledgments}

The authors would like to express their appreciation to all participants of this study and wish to acknowledge Ms. Niloofar Shiva for critical editing of English grammar and syntax of the manuscript.

\section{Availability of data and materials}

Please contact Dr. Azita Zadeh-Vakili (vakili@endocrine.ac.ir) for any data request.

\section{Authors' contributions}

FA, PA and SJF designed the study. SJF, GVN and GA drafted the manuscript. MK carried out the statistical analysis and contributed to interpretation of data. FA revised the manuscript critically for important intellectual content. PA supervised and revised the manuscript. All authors read and approved the final manuscript.

Ethics approval and consent to participate

This study was approved by the research ethics committee of the Research Institute for Endocrine Sciences (RIES), Shahid Beheshti University of Medical Sciences. All participants of this study signed informed consent forms prior to data collection.

Competing interests

The authors declare that they have no competing interests. 


\section{Publisher's Note}

Springer Nature remains neutral with regard to jurisdictional claims in published maps and institutional affiliations.

\section{Author details}

'Research Center for Social Determinants of Health, Research Institute for Endocrine Sciences, Shahid Beheshti University of Medical Sciences, P.O.Box 19395-4763, Tehran, IR, Iran. ${ }^{2}$ Department of Epidemiology and Biostatistics, School of Public Health, Tehran University of Medical Sciences, Tehran, Iran. ${ }^{3}$ Endocrine Research Center, Research Institute for Endocrine Sciences, Shahid Beheshti University of Medical Sciences, Tehran, Iran.

Received: 14 February 2018 Accepted: 27 April 2018 Published online: 10 May 2018

\section{References}

1. Boutayeb A, Boutayeb S. The burden of non communicable diseases in developing countries. Int J Equity Health. 2005;4(1):1.

2. Kivits J, Erpelding M-L, Guillemin F. Social determinants of health-related quality of life. Rev Epidemiol Sante Publique. 2013;61:S189-S94.

3. Tengland P-A. The goals of health work: quality of life, health and welfare. Med Health Care Philos. 2006;9(2):155-67.

4. Bonomi AE, Patrick DL, Bushnell DM, Martin M. Validation of the United States' version of the World Health Organization quality of life (WHOQOL) instrument. J Clin Epidemiol. 2000;53(1):1-12.

5. Amiri P, Hosseinpanah F, Rambod M, Montazeri A, Azizi F. Metabolic syndrome predicts poor health-related quality of life in women but not in men: Tehran lipid and glucose study. J Women's Health. 2010;19(6):1201-7.

6. Rollero C, Gattino S, De Piccoli N. A gender lens on quality of life: the role of sense of community, perceived social support, self-reported health and income. Soc Indic Res. 2014;116(3):887-98.

7. Tartaglia S. Different predictors of quality of life in urban environment. Soc Indic Res. 2013:113(3):1045-53.

8. Rüesch P, Graf J, Meyer P, Rössler W, Hell D. Occupation, social support and quality of life in persons with schizophrenic or affective disorders. Soc Psychiatry Psychiatr Epidemiol. 2004;39(9):686-94

9. Fassio O, Rollero C, De Piccoli N. Health, quality of life and population density: a preliminary study on "contextualized" quality of life. Soc Indic Res. 2013:110(2):479-88.

10. Sazlina S, Zaiton A, Afiah MN, Hayati K. Predictors of health related quality of life in older people with non-communicable diseases attending three primary care clinics in Malaysia. J Nutr Health Aging. 2012;16(5):498-502.

11. Datta D, Datta PP, Majumdar KK. Role of social interaction on quality of life. National J Med Res. 2015;5(4):290-2.

12. Reinfjell T, Tremolada M, Zeltzer LK. A review of demographic, medical, and treatment variables associated with health-related quality of life (HRQOL) in survivors of hematopoietic stem cell (HSCT) and bone marrow transplantation (BMT) during childhood. Front Psychol. 2017;8:253. https://doi.org/10.3389/fpsyg.2017.00253.

13. Zimet GD, Dahlem NW, Zimet SG, Farley GK. The multidimensional scale of perceived social support. J Pers Assess. 1988;52(1):30-41.

14. Gattino S, Rollero C, De Piccoli N. The influence of coping strategies on quality of life from a gender perspective. Appl Res Quality Life. 2015;10(4):689-701.

15. Courtens A, Stevens F, Crebolder H, Philipsen H. Longitudinal study on quality of life and social support in cancer patients. Cancer Nurs. 1996;19(3):162-9.

16. Hardan-Khalil K, Mayo AM. Psychometric properties of the multidimensional scale of perceived social support. Clin Nurse Specialist. 2015;29(5):258-61.

17. Wang H-H, Wu S-Z, Liu Y-Y. Association between social support and health outcomes: a meta-analysis. Kaohsiung J Med Sci. 2003;19(7):345-50.

18. Cobb S. Social support as a moderator of life stress. Psychosom Med. 1976;38(5):300-14

19. Thoits PA. Social support as coping assistance. J Consult Clin Psychol. 1986:54(4):416.

20. Schwarzer R, Knoll N, Rieckmann N. Social support. Health Psychol. 2004;158:181.

21. Haber MG, Cohen JL, Lucas T, Baltes BB. The relationship between self-reported received and perceived social support: a meta-analytic review. Am J Community Psychol. 2007;39(1-2):133-44.
22. Gottlieb BH, Bergen AE. Social support concepts and measures. J Psychosom Res. 2010;69(5):511-20.

23. Ekbäck MP, Lindberg M, Benzein E, Årestedt K. Social support: an important factor for quality of life in women with hirsutism. Health Qual Life Outcomes. 2014;12(1):1.

24. Tremolada M, Bonichini S, Basso G, Pillon M. Perceived social support and health-related quality of life in AYA cancer survivors and controls. Psychooncology. 2016; 25(12):1408-17.

25. Paterson C, Jones M, Rattray J, Lauder W. Exploring the relationship between coping, social support and health-related quality of life for prostate cancer survivors: a review of the literature. Eur J Oncol Nurs. 2013;17(6):750-9.

26. Zheng Y, Ye D-Q, Pan H-F, Li W-X, Li L-H, Li J, et al. Influence of social support on health-related quality of life in patients with systemic lupus erythematosus. Clin Rheumatol. 2009;28(3):265-9.

27. Colloca G, Colloca P. The effects of social support on health-related quality of life of patients with metastatic prostate Cancer. J Cancer Educ. 2016:31(2):244-52

28. Gielen A, McDonnell K, Wu A, O'campo P, Faden R. Quality of life among women living with HIV: the importance violence, social support, and self care behaviors. Soc Sci Med. 2001;52(2):315-22.

29. Ibrahim N, Desa A, Chiew-Tong NK, Ismail R, Zainah A. Social support and religious coping strategies in health-related quality of life of end-stage renal disease patients. Pertanika J Soc Sci Humanit. 2011;19:91-7.

30. Ibrahim N, Teo SS, Din NC, Gafor AHA, Ismail R. The role of personality and social support in health-related quality of life in chronic kidney disease patients. PLoS One. 2015;10(7):e0129015.

31. Costa DC, Sá MJ, Calheiros JM. The effect of social support on the quality of life of patients with multiple sclerosis. Arq Neuropsiquiatr. 2012;70(2):108-13.

32. Wedgeworth M, LaRocca MA, Chaplin WF, Scogin F. The role of interpersonal sensitivity, social support, and quality of life in rural older adults. Geriatr Nurs. 2016.

33. Hajek A, Brettschneider C, Lange C, Posselt T, Wiese B, Steinmann S, et al. Gender differences in the effect of social support on health-related quality of life: results of a population-based prospective cohort study in old age in Germany. Qual Life Res. 2016;25(5):1159-68.

34. Xing H, Yu W, Chen S, Zhang D, Tan R. Influence of social support on health-related quality of life in new-generation migrant workers in eastern China. Iran J Public Health. 2013:42(8):806.

35. Rostami A, Ghazinour M, Nygren L, Nojumi M, Richter J. Health-related quality of life, marital satisfaction, and social support in medical staff in Iran. Appl Res Quality Life. 2013;8(3):385-402.

36. Gallicchio L, Hoffman SC, Helzlsouer KJ. The relationship between gender, social support, and health-related quality of life in a community-based study in Washington County, Maryland. Qual Life Res. 2007;16(5):777-86.

37. Charkhian A, Fekrazad H, Sajadi H, Rahgozar M, Abdolbaghi MH, Maddahi S. Relationship between health-related quality of life and social support in HIV-infected people in Tehran, Iran. Iran J Public Health. 2014:43(1):100.

38. Rambod M, Rafii F. Perceived social support and quality of life in Iranian hemodialysis patients. J Nurs Scholarsh. 2010:42(3):242-9.

39. Rostami Z, Lessan Pezeshki M, Soleimani Najaf Abadi A, Einollahi B. Health related quality of life in Iranian hemodialysis patients with viral hepatitis: changing epidemiology. Hepat Mon. 2013;13(6):e9611.

40. Nekouei ZK, Yousefy A, Doost HTN, Manshaee G, Sadeghei M. Structural model of psychological risk and protective factors affecting on quality of life in patients with coronary heart disease: a psychocardiology model. J Res Medical Sci. 2014;19(2):90.

41. Azizi F, Rahmani M, Emami H, Mirmiran P, Hajipour R, Madjid M, et al. Cardiovascular risk factors in an Iranian urban population: Tehran lipid and glucose study (phase 1). Sozial-und Präventivmedizin/Social and Preventive Medicine. 2002:47(6):408-26.

42. Bagherian-Sararoudi R, Hajian A, Ehsan HB, Sarafraz MR, Zimet GD. Psychometric properties of the persian version of the multidimensional scale of perceived social support in Iran. Int J Prev Med. 2013;4(11):1277-81.

43. Montazeri A, Vahdaninia M, Mousavi SJ, Omidvari S. The Iranian version of 12-item short form health survey (SF-12): factor structure, internal consistency and construct validity. BMC Public Health. 2009:9:341. https://doi.org/10.1186/1471-2458-9-341.

44. Kline RB. Principles and practice of structural equation modeling. 4th Edition. New York: Guilford publications; 2015.

45. Hooper D, Coughlan J, Mullen M. Structural equation modelling. Guidelines for determining model fit. Articles. 2008. p. 53-60. 
46. Duffy ME. Social networks and social support of recently divorced women Public Health Nurs (Boston, Mass). 1993;10(1):19-24.

47. Cairney J, Boyle M, Offord DR, Racine Y. Stress, social support and depression in single and married mothers. Soc Psychiatry Psychiatr Epidemiol. 2003;38(8):442-9. https://doi.org/10.1007/s00127-003-0661-0.

48. Adamczyk K. An investigation of loneliness and perceived social support among single and partnered young adults. Current Psychol (New Brunswick, NJ). 2016;35(4):674-89. https://doi.org/10.1007/s12144-015-9337-7.

49. Rambod M, Rafii F. Perceived social support and quality of life in Iranian hemodialysis patients. Journal of nursing scholarship : an official publication of sigma Theta tau international honor society of. Nursing. 2010;42(3):242-9. https://doi.org/10.1111/j.1547-5069.2010.01353.X.

50. Masoudnia E. Relationship between perceived social support and risk of postpartum depression disorder. Iran J Nurs. 2011;24(70):8-18.

51. Rohrer JE, Bernard ME, Zhang Y, Rasmussen NH, Woroncow H. Marital status, feeling depressed and self-rated health in rural female primary care patients. J Eval Clin Pract. 2008;14(2):214-7.

52. Lindström M. Marital status, social capital, material conditions and self-rated health: a population-based study. Health Policy. 2009;93(2):172-9.

53. Soulsby LK, Bennett KM. Marriage and psychological wellbeing: the role of social support. Psychology. 2015;6(11):1349.

54. Trevisol DJ, Moreira LB, Kerkhoff A, Fuchs SC, Fuchs FD. Health-related quality of life and hypertension: a systematic review and meta-analysis of observational studies. J Hypertens. 2011;29(2):179-88.

55. Saboya PP, Bodanese LC, Zimmermann PR, Gustavo AdS, Assumpção CM, Londero F. Metabolic syndrome and quality of life: a systematic review. Rev Lat Am Enfermagem 2016;24.

56. Thommasen $\mathrm{H}$, Zhang $\mathrm{W}$. Impact of chronic disease on quality of life in the Bella Coola Valley. Rural Remote Health. 2006;6(2):528.

57. Kiadaliri AA, Najafi B, Mirmalek-Sani M. Quality of life in people with diabetes: a systematic review of studies in Iran. J Diabetes Metab Disord. 2013;12(1):54.

\section{Ready to submit your research? Choose BMC and benefit from:}

- fast, convenient online submission

- thorough peer review by experienced researchers in your field

- rapid publication on acceptance

- support for research data, including large and complex data types

- gold Open Access which fosters wider collaboration and increased citations - maximum visibility for your research: over $100 \mathrm{M}$ website views per year

At BMC, research is always in progress.

Learn more biomedcentral.com/submissions 